Conclusions The proportion of patients analysed and the HBV sequence changes observed were similar between patients in the TAF and TDF arms. Most substitutions occurred at polymorphic positions and no substitutions associated with resistance to TAF were detected through 96 weeks of treatment.

\section{IDDF2018-ABS-0107 EFFICACY AND SAFETY OF TENOFOVIR ALAFENAMIDE (TAF) AT 96 WEEKS IN CHRONIC HBV (CHB) PATIENTS WITH RISK FACTORS FOR USE OF TENOFOVIR DISOPROXIL FUMARATE (TDF)}

${ }^{1}$ Henry Lik-Yuen Chan*, ${ }^{2}$ Maria Buti, ${ }^{3}$ Robert Flisiak, ${ }^{4}$ Stephen Ryder, ${ }^{5}$ Adrian StreinuCercel, ${ }^{6} J o h n$ F Flaherty, ${ }^{6}$ Anuj Gaggar, ${ }^{6}$ Shuyuan Mo, ${ }^{6} \mathrm{G}$ Mani Subramanian, ${ }^{7}$ Fabrian Zoulim, ${ }^{8}$ Pietro Andreone, ${ }^{9}$ Patrick Marcellin. ${ }^{1}$ Department of Medicine and Therapeutics, Institute of Digestive Disease and State Key Laboratory of Digestive Disease, The Chinese University of Hong Kong, Hong Kong; ${ }^{2}$ Hospital General Universitari Vall d'Hebron, Barcelona, Spain; ${ }^{3}$ Medical University of Bialystok, Bialystok, Poland; ${ }^{4}$ Nottingham University Hospital, Nottingham, UK; ${ }^{5}$ Carol Davila University of Medicine and Pharmacy, Bucharest, Romania; ${ }^{6}$ Gilead Sciences, Foster City, CA, USA; ${ }^{7}$ Hopital de la Croix Rousse, Lyon, France; ${ }^{8}$ University of Bologna, Bologna, Italy; ${ }^{9}$ Hopital Beaujon, Clichy, France

\subsection{6/gutjnl-2018-IDDFabstracts.208}

Background The recently updated EASL Guidelines for Management of HBV Infection (2017) recommend the use of TAF as an alternative to TDF in patients with risk factors unfavourable to TDF use. We, therefore, performed an evaluation of the efficacy and safety of TAF compared with TDF in patients considered to be at risk for adverse bone and/or renal effects from TDF.

\begin{tabular}{|c|c|c|c|}
\hline $\mathrm{n} / \mathrm{N}(\%)$ & $\begin{array}{c}\text { TAF } \\
(n=151)\end{array}$ & $\begin{array}{c}\text { TDF } \\
(\mathrm{n}=88)\end{array}$ & $P$ value \\
\hline \multicolumn{4}{|l|}{ Bone parameters } \\
\hline Hip BMD, mean (SD)\% change ${ }^{a}$ & $-0.28(2.50)$ & $-2.16(3.10)$ & $<0.001$ \\
\hline Spine $B M D$, mean $(S D) \%$ change & $-1.35(4.46)$ & $-2.46(3.73)$ & 0.071 \\
\hline \multicolumn{4}{|l|}{$\begin{array}{l}\text { Serum bone biomarkers, median (Q1, Q3)\% } \\
\text { change }\end{array}$} \\
\hline C-type collagen sequence (CTX) [resorption] & $\begin{array}{c}-3.9(-25.5 \\
24.1)\end{array}$ & $\begin{array}{c}37.7(9.1- \\
92.9)\end{array}$ & $<0.001$ \\
\hline $\begin{array}{l}\text { Procollagen type } 1 \mathrm{~N} \text {-terminal propeptide } \\
\text { (P1NP) [formation] }\end{array}$ & $\begin{array}{c}-18.3(-34.0 \\
8.99)\end{array}$ & $\begin{array}{c}8.7(-14.4 \\
42.5)\end{array}$ & $<0.001$ \\
\hline Osteocalcin (OC) [formation] & $\begin{array}{c}4.5(-13.4, \\
20.8)\end{array}$ & $\begin{array}{c}34.8(7.5- \\
54.2)\end{array}$ & $<0.001$ \\
\hline \multicolumn{4}{|l|}{ Renal parameters } \\
\hline eGFR $_{\mathrm{CG}}$ median(Q1, Q3) change $(\mathrm{mL} / \mathrm{min})^{\mathrm{b}}$ & $\begin{array}{c}-2.4(-8.4 \\
6.2)\end{array}$ & $\begin{array}{c}-6.7(-15.0 \\
2.4)\end{array}$ & 0.008 \\
\hline \multicolumn{4}{|l|}{ Urine biomarkers, median(Q1, Q3)\% change } \\
\hline Protein/creatinine ratio, mg/g & $\begin{array}{c}-17.5(-49.5 \\
38.7)\end{array}$ & $\begin{array}{c}6.9(-39.8 \\
53.3)\end{array}$ & 0.18 \\
\hline Albumin/creatinine ratio, mg/g & $\begin{array}{l}10.4(-34.4 \\
87.4)\end{array}$ & $\begin{array}{c}10.7(-47.6 \\
73.0)\end{array}$ & 0.44 \\
\hline Retinol binding protein/creatinine ratio, $\mu \mathrm{g} / \mathrm{g}$ & $\begin{array}{l}13.1(-17.1 \\
79.1)\end{array}$ & $\begin{array}{c}48.4(-2.0 \\
127.8)\end{array}$ & 0.014 \\
\hline Beta-2 microglobulin/creatinine ratio, $\mu \mathrm{g} / \mathrm{g}$ & $\begin{array}{c}6.2(-28.3 \\
62.9)\end{array}$ & $\begin{array}{c}55.2(0.3- \\
248.0)\end{array}$ & $<0.001$ \\
\hline
\end{tabular}

${ }^{\mathrm{a} B M D}$ is bone mineral density by DXA scan; ${ }^{\mathrm{b}}$ eGFR $\mathrm{RG}_{\mathrm{CG}}$ is creatinine clearance (CockcroftGault method)

Methods In two Phase 3 studies, patients (HBeAg-positive $[\mathrm{n}=873]$ and $\mathrm{HBeAg}$-negative $[\mathrm{n}=425])$ were randomised 2:1 to TAF or TDF. Antiviral efficacy (HBV DNA $<29 \mathrm{IU} / \mathrm{mL}$ ) and ALT normalisation (by central laboratory and AASLD criteria) were assessed by study and safety results were pooled for bone (serial DXA scans at hip/spine and serum bone biomarkers) and renal parameters (eGFR by Cockcroft-Gault [eGFR $\left.\mathrm{CG}_{\mathrm{CG}}\right]$ and urine biomarkers of tubular function) and assessed over 96 weeks in the subset with baseline risk factors for TDF use: Age $>60$ years, osteoporosis of hip or spine by t-score, eGFR $\mathrm{CG}<60 \mathrm{~mL} / \mathrm{min}$, urine albumin to creatinine ratio $>30 \mathrm{mg} / \mathrm{g}$, or serum phosphorus $<2.5 \mathrm{mg} / \mathrm{dL}$.

Results Of 1298 patients randomised and treated in the 2 studies, 239 (18\%; 151 TAF and 88 TDF) patients had at least 1 risk factor for TDF use. Baseline demographics were similar between groups. At Week 96, similar antiviral efficacy (HBV DNA $<29 \mathrm{IU} / \mathrm{mL}$ ), and higher rates of ALT normalisation were seen in the TAF compared with the TDF group which were comparable to the overall results in these studies. Significant differences in favour of TAF were observed in key bone and renal safety parameters (table 1). Patients receiving TAF had smaller declines in BMD, particularly at the hip, and smaller changes in markers of bone resorption and formation. TAF-treated patients also showed smaller declines in eGFR $_{\mathrm{CG}}$ with significantly smaller increases in markers of tubular function.

Conclusions In $\mathrm{CHB}$ patients considered to be at risk for TDF toxicity, TAF showed significantly less impact on bone and renal parameters while efficacy was maintained in this subgroup through 96 weeks.

\section{IDDF2018-ABS-0108 IMPROVED BONE AND RENAL SAFETY AT 1 YEAR AFTER SWITCHING FROM TENOFOVIR DISOPROXIL FUMARATE (TDF) TO TENOFOVIR ALAFENAMIDE (TAF): RESULTS FROM 2 PHASE 3 STUDIES IN HBEAG- POSITIVE AND HBEAG-NEGATIVE PATIENTS WITH CHRONIC HEPATITIS B (CHB)}

${ }^{1}$ Henry Lek-Yuen Chan* ${ }^{2}$ Calvin Pan, ${ }^{3}$ Maurizia Brunetto, ${ }^{4}$ Aric Josun Hui, ${ }^{5}$ Rajiv Mehta ${ }^{6}$ John F Flaherty, ${ }^{6}$ Vithika Suri, ${ }^{6}$ George Wu, ${ }^{6}$ Anuj Gaggar, ${ }^{6} \mathrm{G}$ Mani Subramanian, ${ }^{7}$ Shuhei Nishiguchi, ${ }^{8}$ Hyung Joon Kim, ${ }^{9}$ Edward Gane, ${ }^{10}$ Wan Long Chuang. ${ }^{1}$ Department of Medicine and Therapeutics, Institute of Digestive Disease and State Key Laboratory of Digestive Disease, The Chinese University of Hong Kong, Hong Kong; ${ }^{2}$ New Discovery LLC, Flushing, NY, USA; ${ }^{3}$ Uo Epatologia-Azienda Ospedaliero Universitaria Pisana, Italy; ${ }^{4}$ Alice Ho Miu Ling Nethersole Hospital, Hong Kong; ${ }^{5}$ Liver Clinic ,Surat, India; ${ }^{6}$ Gilead Sciences, Foster City, CA, USA; 'Department of Internal Medicine, Hyogo College of Medicine, Nishinomiya, Japan; ${ }^{8}$ Division of Gastroenterology and Hepatology, Chungang University Hospital, College of Internal Medicine, Korea, South; ${ }^{9}$ Auckland City Hospital, New Zealand; ${ }^{10}$ Kaohsiung Medical University Hospital, Kaohsiung, Taiwan

\subsection{6/gutjnl-2018-IDDFabstracts.209}

Background TAF has shown less bone and renal effects with similar efficacy rates compared to TDF in Phase 3 studies after 96 weeks of double-blind (DB) treatment. We evaluated patients who completed 96 weeks of DB treatment with TAF or TDF and switched to open label (OL) treatment with TAF, including those with 1 year of data (through Week 144) to 